\title{
Risk of SARS-CoV2-related Mortality in Non-small Cell Lung Cancer Patients Treated With First-line Immunotherapy Alone or in Combination With Chemotherapy
}

Giuseppe Luigi Banna ( $\square$ giuseppe.banna@nhs.net )

Queen Alexandra Hospital

\section{Ornella Cantale}

The Mediterranean Institution of Oncology https://orcid.org/0000-0002-6305-3340

\section{Alex Friedlaender}

Geneva University Hospitals: Hopitaux Universitaires Geneve

Harliana Yusof

Queen Alexandra Hospital

\section{Alfredo Addeo}

Geneva University Hospitals: Hopitaux Universitaires Geneve

\section{Research Article}

Keywords: SARS-CoV-2, mortality, lung cancer, immunotherapy, PD1, PD-L1, neutrophil-to-lymphocyte ratio (NLR), systemic immune-inflammation index (SII)

Posted Date: February 8th, 2021

DOl: https://doi.org/10.21203/rs.3.rs-167896/v1

License: (c) (i) This work is licensed under a Creative Commons Attribution 4.0 International License.

Read Full License

Version of Record: A version of this preprint was published at Cancer Investigation on August 19th, 2021. See the published version at https://doi.org/10.1080/07357907.2021.1970761. 


\section{Abstract}

Background: Patients with cancer are vulnerable to severe acute respiratory syndrome coronavirus 2 (SARS-CoV-2), although the impact of solid cancer types and systemic anticancer treatments on its related mortality is still debatable.

Methods: To weigh the real impact of immune-checkpoint inhibitors (ICls) by exploring the risk of SARSCoV-2-related mortality in a retrospective analysis of patients with non-small-cell lung cancer (NSCLC) treated with first-line Pembrolizumab or in combination with chemotherapy (ChT) during the first surge of the pandemic.

Results: The risk of death was significantly higher in the group of patients treated with ChT+Pembrolizumab than with Pembrolizumab alone (OR 2.43 (1.23-4.82, p=0.01). The SARS-CoV-2related mortality rate was $8 \%$ and significantly associated with ChT+Pembrolizumab as compared to Pembrolizumab alone ( $18 \%$ vs. $0 \%$, respectively, $p=0.03$ ). Patients dead because of SARS-CoV- 2 were older than 70 years (100 vs. $34 \%$, respectively, $p=0.03$ ) and tended to have a heavier smoking history (67 vs. $29 \%$ of current smokers, respectively, $p=0.17$ ). Higher baseline values of neutrophil-to-lymphocyte ratio (NLR) (with 67 vs. $50 \% \geq 4.0, p=0.58$ ) and systemic immune-inflammation index (SII) (with 67 vs. $50 \% \geq$ $1236, p=0.58$ ) were observed in patients dead due to the SARS-CoV-2.

Conclusions: Immunotherapy might not impact the risk of SARS-CoV-2-related mortality, whilst the addition of ChT was either associated with an overall increased risk of mortality and to the risk of SARSCoV-2-related mortality. The co-existence of other clinical factors may have contributed to the latter.

\section{Background}

Severe acute respiratory syndrome coronavirus 2 (SARS-CoV-2) is a novel crown-like enveloped RNA virus responsible for COVID-19 disease[1]. COVID-19 displays more frequently mild severity symptoms and, rarely, respiratory failure, cytokine release syndrome (CRS) and multi-organ failure[2]. Overall, it is accountable for a case-fatality rate ranging from 2 to $3 \%[1]$. New variants of COVID-19 are emerging, particularly the "VUI-202012/01" (i.e. "variant under investigation") is rapidly spreading in the UK and is characterized by increased transmissibility of up to $71 \%$ over and above the previous circulating strains of SARS-CoV-2, although there is no evidence of increased clinical severity of illness or vaccine escape capability[3].

Cancer patients are considered a vulnerable category, due to the impact of the malignancy and anticancer treatments on immunological impairment[1]. Moreover, as a consequence of the pandemic restrictions, oncological care is lacking in terms of timely diagnoses and treatment deliveries, resulting in an increased rate of disease progression[1]. To ensure public surveillance to this community, the UK Coronavirus Cancer Monitoring Project (UKCCMP) had been launched in March 2020, a large prospective database of COVID-19 in patients with cancer[4]. 
The pooled prevalence of cancer in patients with COVID-19 is estimated as $2.0 \%(95 \% \mathrm{Cl}, 2.0$ to $3.0 \mathrm{I} 2=$ $83.2 \%$ ) compared to an approximately $0.3 \%$ incidence of cancer and $0.37 \%$ of COVID-19 infection in the overall population[5]. Patients with cancer, particularly with thoracic malignancies, have poorer outcomes than the overall population[6]. However, this concept has been challenged by the results of a prospective study conducted by Lee L. et al, on a cohort of 800 patients, with $226(28 \%)$ deceased patients, in the largest majority due to COVID-19 (211 [93\%]). Crucial risk factors emerged were age (median age was 73.0 years vs. 66.0 years, $p<0.001)$, male gender $(146,[33 \%]$ of 449$)$ rather than female gender $(80$ [20\%] of 349$)$, and comorbidities as cardiovascular disease ( $21 \%$ vs. $11 \%, p<0.001)$, hypertension $(41 \%$ vs. $27 \%, p<0.001)$ and dyspnoea ( $57 \%$ vs. $32 \%, p<0.001)[4]$. Cytotoxic chemotherapy, immunotherapy, hormonal therapy, targeted therapy and radiotherapy were compared in this dataset. After adjusting for other risk factors, the multivariate analysis concluded that treatment within 4 weeks before confirmed COVID-19 is neither determining for a more severe disease nor predictive of COVID-19-related death, questioning the actual impact of cancer treatments[4]. Moreover, a further researchers' query was to investigate COVID-19 risk according to tumour subtypes. Lee et al. found through a prospective cohort study that cancer type was not a risk factor for increased case-fatality rate, exception made for haematological malignancies (odds ratio [OR] 2.25, 95\% Cl 1.13-4.57; P=0.023); this applies to lung cancer too[2].

This evidence challenges the results coming from the TERAVOLT registry study, collecting patients' data from 42 institutions across eight countries (Italy, Spain, France, Switzerland, Netherlands, USA, UK and China) addressed to study the impact of COVID-19 in patients with thoracic cancers. According to Garassino M.C. et al., patients infected by COVID-19 hit a mortality rate of $33 \%$ regardless of their specific systemic treatments[7]. This evidence supported the current recommendation of postponing unnecessary active cancer treatments at least during the COVID-19 pandemic surges[8, 9]. This applies for both chemotherapy (ChT), on the premises of a consequent potential immunosuppression, and for immunecheckpoint inhibitors (ICls), due to potential albeit rare and life-threatening immune-related adverse events (irAEs). Among these, interstitial pneumonia represents possible toxicity from anti-programmed cell death (PD)-1/PD-ligand(L) 1 agents and could be associated with a CRS, with a surge of IL- 6 and IFN$y$ levels ${ }^{8}$. According to Luo $\mathrm{J}$ et al, in a series of 41 infected patients between those exposed or not to PD1 blockade, no significant difference in the severity of SARS-CoV-2 and IL-6 peaks was observed, although these data, as for the most of the available evidence, refer to patients infected by COVID-19 without considering the overall population of patients treated with ICIs[10].

The analysis hereby weighs the real impact of ICls by exploring the risk of SARS-CoV-2-related mortality in patients with NSCLC treated with first-line immunotherapy alone or in combination with chemotherapy (ChT) during the first surge of the pandemic.

\section{Methods}

Relevant clinical and treatment-related data of patients with histological diagnosis of NSCLC, known PDL1 status, clinical stage IIIB-IV according to the TNM classification v8.0, on treatment with first-line 
Pembrolizumab or ChT in combination with Pembrolizumab between the January 2020 and May 2020, were retrospectively reviewed in two European centres in the UK and Switzerland. The C39 code from the International Classification of Diseases (10th edition) and the term "Pembrolizumab" were used to identify the relevant patients from the electronic database. Briefly, we considered the following characteristics: age, sex, smoking status, country, disease stage, Eastern Cooperative Oncology Group (ECOG) Performance Status (PS), autoimmune disease, PD-L1 expression, histology, chemotherapy, neutrophil-to-lymphocyte ratio (NLR), systemic immune-inflammation index (SII) (or the NLR x platelets). The baseline NLR and SII were calculated from reports of routine blood yielded within seven days from treatment start according to local laboratories. This retrospective analysis was conducted following the Declaration of Helsinki and involved a real-world series of patients treated according to the clinical practice; ethical approval was waived because all patients in each Centre signed a specific consent form for their data collection and sharing with other Institutions.

We described the overall mortality rate, the death-related causes, and the clinical features of dead patients. Descriptive statistics were used to summarize the patient demographic and treatment characteristics, with medians and proportions as appropriate. Statistical significance of variable across the two groups was investigated by Chi-square and Mann-Whitney $U$ tests for dichotomous and continuous variables, respectively, with an acceptable significance value of $p<0.05$. The OS was calculated from the date of treatment start until death or date of the last follow-up and was estimated using the Kaplan-Meier method reported as medians with confidence limits (95\% $\mathrm{CI})$ and compared using the two-sided log-rank test, with an acceptable significance value of $p<0.05$. Patients who did not have events at the time of the analysis were censored. Univariable logistic regression analysis was used for the association of treatment and death rate by computing Odds-ratio (OR) with $95 \%$ confidence intervals (Cls) and alpha level set to $p<0.05$.

\section{Results}

The clinical characteristics of the 111 patients included in the analysis are summarised in Table 1. Sixtysix patients (59\%) were on Pembrolizumab and 45 (41\%) on combination therapy with chemotherapy (ChT) and Pembrolizumab. There was an expected significant difference between treatment cohorts and PD-L1 expression, as Pembrolizumab alone was offered only to those patients with PD-L1 tumour expression $>50 \%$ (100\%), whereas only two (4\%) in the ChT + Pembrolizumab cohort had a PD-L $1>50 \%$ $(p<0.001)$. Other significant differences between the two treatment cohorts regarded a higher prevalence of PS 2 in the Pembrolizumab group ( $9 \%$ vs. 0\%, p = 0.04) and non-squamous histology in the ChT+ Pembrolizumab group ( $84 \%$ vs. 58\%, $p=0.003$ ); a nonsignificant trend toward to older patients' age in the Pembrolizumab cohort was observed (47\% vs. $31 \%, p=0.09)$. 
Table 1

Characteristics of patients

\begin{tabular}{|c|c|c|c|c|}
\hline & $\begin{array}{l}\text { All } \\
\text { patients } \\
n=111 \\
n\end{array}$ & $\begin{array}{l}\text { Pembro alone } n=66 \\
(59 \%) \\
n(\%)\end{array}$ & $\begin{array}{l}\text { ChT + Pembro } \\
n=45(41 \%) \\
n(\%)\end{array}$ & $P$ value \\
\hline Age, years, median & & $68(40-82)$ & $66(40-81)$ & 0.12 \\
\hline (Ininge & 8 & $3(5)$ & $5(11)$ & 0.19 \\
\hline $50-70$ & 58 & $32(48)$ & $26(58)$ & 0.34 \\
\hline$>70$ & 45 & $31(47)$ & $14(31)$ & 0.09 \\
\hline \multicolumn{5}{|l|}{ Sex } \\
\hline Female & 40 & $24(36)$ & $16(36)$ & 0.93 \\
\hline Male & 71 & $42(64)$ & $29(64)$ & \\
\hline \multicolumn{5}{|l|}{ Smoking status } \\
\hline Current & 35 & $18(27)$ & $17(38)$ & 0.24 \\
\hline Former & 69 & $45(68)$ & $24(53)$ & 0.11 \\
\hline Never & 7 & $3(5)$ & $4(9)$ & 0.36 \\
\hline \multicolumn{5}{|l|}{ Country } \\
\hline UK & 63 & $39(59)$ & $24(53)$ & 0.55 \\
\hline Switzerland & 48 & $27(41)$ & $21(47)$ & \\
\hline \multicolumn{5}{|l|}{ Disease stage } \\
\hline $\mathrm{IIIB} / \mathrm{C}$ & 9 & $7(11)$ & $2(4)$ & 0.24 \\
\hline IVA & 47 & $28(42)$ & $19(42)$ & 0.98 \\
\hline IVB & 55 & $31(47)$ & $24(53)$ & 0.51 \\
\hline \multicolumn{5}{|l|}{ ECOG PS } \\
\hline 0 & 46 & $24(36)$ & $22(49)$ & 0.19 \\
\hline 1 & 59 & $36(55)$ & $23(51)$ & 0.72 \\
\hline 2 & 6 & $6(9)$ & $0(0)$ & 0.04 \\
\hline
\end{tabular}




\begin{tabular}{|c|c|c|c|c|}
\hline & $\begin{array}{l}\text { All } \\
\text { patients } \\
n=111 \\
n\end{array}$ & $\begin{array}{l}\text { Pembro alone } n=66 \\
(59 \%) \\
n(\%)\end{array}$ & $\begin{array}{l}\text { ChT + Pembro } \\
n=45(41 \%) \\
n(\%)\end{array}$ & $P$ value \\
\hline \multicolumn{5}{|l|}{ Autoimmune disease } \\
\hline Yes & 6 & $3(5)$ & $3(7)$ & \multirow[t]{2}{*}{0.63} \\
\hline No & 105 & $63(95)$ & $42(93)$ & \\
\hline \multicolumn{5}{|l|}{ PD-L1 } \\
\hline$<1 \%$ & 25 & $0(0)$ & $25(56)$ & NA \\
\hline $1-49 \%$ & 19 & $0(0)$ & $18(40)$ & NA \\
\hline$>50 \%$ & 67 & $66(100)$ & $2(4)$ & $<0.001$ \\
\hline \multicolumn{5}{|l|}{ Histology } \\
\hline Non-squamous & 76 & $38(58)$ & $38(84)$ & \multirow[t]{2}{*}{0.003} \\
\hline Squamous & 35 & $28(42)$ & $7(16)$ & \\
\hline \multicolumn{5}{|l|}{ Chemotherapy } \\
\hline Cis/Carbo-Pem & 37 & - & $37(82)$ & NA \\
\hline Cis/Carbo-Pac & 8 & - & $8(18)$ & NA \\
\hline NLR median (range) ${ }^{a}$ & & $4.3(1.0-19.6)$ & $4.0(1.1-84.0)$ & 0.98 \\
\hline$<4.0$ & 53 & $31(48)$ & $22(48)$ & \multirow[t]{3}{*}{0.96} \\
\hline$\geq 4.0$ & 56 & $33(52)$ & $23(51)$ & \\
\hline missing & 2 & $2(3)$ & $0(0)$ & \\
\hline \multicolumn{2}{|l|}{ SII median (range) ${ }^{a}$} & $1314(233-7708)$ & \multirow{2}{*}{$\begin{array}{l}1236(388- \\
11426)\end{array}$} & \multirow{4}{*}{$\begin{array}{l}0.94 \\
0.71\end{array}$} \\
\hline$<1236$ & 51 & $29(45)$ & & \\
\hline$\geq 1236$ & 58 & $35(55)$ & \multirow{2}{*}{$\begin{array}{l}22(49) \\
23(51) \\
0(0)\end{array}$} & \\
\hline missing & 2 & $2(3)$ & & \\
\hline $\begin{array}{l}\text { Abbreviations: Carbo, C } \\
\text { Oncology Group Perfor } \\
\text { NLR, neutrophil-to-lymp } \\
\text { Pemetrexed; Pembro, P } \\
\\
\text { aAs no validated cut-of } \\
\text { was chosen as cut-off }\end{array}$ & $\begin{array}{l}\text { latin; ChT, } \\
\text { e Status; I } \\
\text { te ratio; PD } \\
\text { olizumab; }\end{array}$ & $\begin{array}{l}\text { motherapy; Cis, cisplat } \\
\text { nmune-checkpoint inhi } \\
\text { programmed cell deat } \\
\text { systemic immune-inflar }\end{array}$ & $\begin{array}{l}\text { G PS, Eastern Cc } \\
\text { number; NA, no } \\
\text { d1; Pac, Paclitax } \\
\text { n index. } \\
\\
\text { erved in the ChT }\end{array}$ & $\begin{array}{l}\text { ative } \\
\text { essable; } \\
\text { m, } \\
\text { group }\end{array}$ \\
\hline
\end{tabular}


The median follow-up and OS were significantly longer for the Pembrolizumab as compared to the ChT + Pembrolizumab cohort ( $p<0.001$ and $p=0.009$, respectively) (see Table 2 ). The risk of death was significantly higher in the group of patients treated with $\mathrm{ChT}+$ Pembrolizumab than with Pembrolizumab alone (OR $2.43(1.23-4.82, \mathrm{p}=0.01)$. 
Table 2

Death rates, risk, causes according to treatment and patients dead features

\begin{tabular}{|c|c|c|c|}
\hline Patients, no. & $\begin{array}{l}\text { Pembro alone } \\
n=66(59 \%)\end{array}$ & $\begin{array}{l}\text { ChT + Pembro } \\
n=45(41 \%)\end{array}$ & $P$ value \\
\hline FU, median, mo. (95\% Cl) & $23.1(19.8-26.5)$ & $11.1(4.1-18.1)$ & $<0.001$ \\
\hline OS, median, mo. (95\% Cl) & $34.6(23.1-46.0)$ & $10.4(\mathrm{NA})$ & 0.009 \\
\hline Death rate, No. (\%) & $21(32 \%)$ & $17(38 \%)$ & 0.52 \\
\hline Death rate, OR (95\%) & 1.0 & $2.43(1.23-4.82)$ & 0.01 \\
\hline \multicolumn{4}{|l|}{ Deaths, causes: } \\
\hline PD & $16(76 \%)$ & $12(71 \%)$ & 0.77 \\
\hline SARS-CoV-2 & $0(0 \%)$ & $3(18 \%)$ & 0.03 \\
\hline Chest infection & $2(10 \%)$ & $0(0 \%)$ & 0.24 \\
\hline Other & $3(14 \%)$ & $2(12 \%)$ & 0.98 \\
\hline \multicolumn{4}{|c|}{ Patients dead $(n=38)$ features according to SARS-CoV-2 } \\
\hline & Not related to & Related to & \\
\hline & SARS-CoV-2 & SARS-CoV-2 & \\
\hline & $n=35(92 \%)$ & $\mathrm{n}=3(8 \%)$ & \\
\hline Age, years, median (range) & $67(48-82)$ & $76(76-80)$ & 0.06 \\
\hline$>70$ & $12(34)$ & $3(100)$ & 0.03 \\
\hline \multicolumn{4}{|l|}{ ECOG PS: } \\
\hline 0 & $18(51)$ & $1(33)$ & 0.55 \\
\hline 1 & $13(37)$ & $2(67)$ & 0.32 \\
\hline 2 & $4(11)$ & $0(0)$ & 0.54 \\
\hline \multicolumn{4}{|l|}{ Smoking: } \\
\hline current & $10(29)$ & $2(67)$ & 0.17 \\
\hline former & $23(66)$ & $1(33)$ & 0.26 \\
\hline never & $2(6)$ & $0(0)$ & 0.67 \\
\hline NLR, median & $4.0(1.0-84.0)$ & $4.5(4.5-32.0)$ & 0.66 \\
\hline$\geq 4.0$ & $17(50)$ & $2(67)$ & 0.58 \\
\hline missing & $1(3)$ & $0(0)$ & \\
\hline
\end{tabular}




\begin{tabular}{|c|c|c|c|}
\hline Patients, no. & $\begin{array}{l}\text { Pembro alone } \\
n=66(59 \%)\end{array}$ & $\begin{array}{l}\text { ChT + Pembro } \\
n=45(41 \%)\end{array}$ & $P$ value \\
\hline SII, median & $1247(233-11340)$ & $1610(427-8276)$ & 0.81 \\
\hline$\geq 1236$ & $17(50)$ & $2(67)$ & 0.58 \\
\hline missing & $1(3)$ & $0(0)$ & \\
\hline \multicolumn{4}{|c|}{$\begin{array}{l}\text { ChT, chemotherapy; } \mathrm{Cl} \text {, confidence interval; ECOG PS, Eastern Cooperative Oncology Group } \\
\text { performance status; FU, follow-up; OR, odds-ratio; mo., months; NA, not assessable; n, number; OS, } \\
\text { overall survival; PD, progressive disease; SARS-CoV-2, severe acute respiratory syndrome coronavirus } \\
2 \text {. }\end{array}$} \\
\hline
\end{tabular}

The SARS-CoV-2-related mortality rate was $8 \%$ and significantly associated with $\mathrm{ChT}+$ Pembrolizumab ( $18 \%$ vs. $0 \%$, respectively, $p=0.03$ ) (see Table 2 ).

Noticeably, as compared to other death causes patients deceased because of SARS-CoV-2 were older than 70 years ( 100 vs. $34 \%$, respectively, $p=0.03$ ) and tended to have a heavier smoking history ( $67 \mathrm{vs.}$ $29 \%$ of current smokers, respectively, $p=0.17$ ). Higher baseline values of NLR (with 67 vs. $50 \% \geq 4.0, p=$ 0.58 ) and SII (with 67 vs. $50 \% \geq 1236, p=0.58$ ) were observed in patients died due to the SARS-CoV-2.

\section{Conclusions}

According to our retrospective analysis based on a population of patients with NSCLC treated with firstline immunotherapy or chemo-immunotherapy unselected for the COVID-19 infection, immunotherapy seemed not impacting on the risk of SARS-CoV-2-related mortality, whilst the addition of ChT was both associated with an increased risk of mortality and to the risk of SARS-CoV-2-related mortality. A not negligible SARS-CoV-2-related mortality of $8 \%$ was observed. Besides the addition of ChT, the coexistence of other clinical factors such as elderly age ( $>70$ years), heavy smoking history and a proinflammatory systemic condition (with high NLR and SII) may have contributed to the SARS-CoV-2-related mortality. Older age, male gender and comorbidities (i.e. hypertension and cardiovascular disease) were specific features of patients with cancer and symptomatic COVID-19 who died by the analysis conducted by Lee et al.[4] Moreover, systemic inflammation may represent a key driver of mortality from SARS-CoV-2 in cancer patients (Dettore) leading to the deterioration of COVID-19, via the CRS and cytokine stormrelated acute respiratory distress syndrome (ARDS)[11]. Relevant limitations of this study are the limited sample of patients, the retrospective nature of the analysis and the lack of a screening for COVID-19. Our findings deserve further confirmation to outline the real risk of SARS-Cov-2 in terms of mortality related to $\mathrm{ICl}$ and/or ChT in NSCLC patients and the role of other clinical features.

\section{Declarations}


Dr. Banna reports personal fees from Janssen Cilag, Boehringer Ingelheim and Roche, outside the submitted work; Dr. Friedlaender reports personal fees from Roche, Pfizer, Astellas and Bristol Myers Squibb, outside the submitted work; Dr. Addeo reports personal fees from BMS, Astrazeneca, Roche, Pfizer, MSD, Boehringer, outside the submitted work. The other authors have no relevant conflicts of interest to declare.

\section{Author contributions:}

(I) Conception and design: GLB, AA; (II) Administrative support: OC; (III) Provision of study materials: All authors; (IV) Collection and assembly of data: AF, GLB, HY; (V) Data analysis and interpretation: All authors; (VI) Manuscript writing: OC, GLB; (VII) Final approval of manuscript: All authors.

\section{Acknowledgements:}

The Authors are grateful to Mediterranean Cancer Support and Rehabilitation - Medicare Onlus, Catania, Italy for the support in data collection and management. This research did not receive any specific grant from funding agencies in the public, commercial, or not-for-profit sectors.

\section{References}

1. Abdihamid O, Cai C, Kapesa L, Zeng S. The Landscape of COVID-19 in Cancer Patients: Prevalence, Impacts, and Recommendations. Cancer Manag Res. 2020;12:8923-33. doi:10.2147/CMAR.S272008.

2. Lee LYW, Cazier JB, Starkey T, Briggs SEW, Arnold R, Bisht V et al. COVID-19 prevalence and mortality in patients with cancer and the effect of primary tumour subtype and patient demographics: a prospective cohort study. The Lancet Oncology. 2020;21(10):1309-16. doi:10.1016/S14702045(20)30442-3.

3. Tang JW, Tambyah PA, Hui DSC. Emergence of a new SARS-CoV-2 variant in the UK. Journal of Infection. 2020. doi:https://doi.org/10.1016/j.jinf.2020.12.024.

4. Lee LY, Cazier J-B, Angelis V, Arnold R, Bisht V, Campton NA et al. COVID-19 mortality in patients with cancer on chemotherapy or other anticancer treatments: a prospective cohort study. Lancet (London, England). 2020;395(10241):1919-26. doi:10.1016/S0140-6736(20)31173-9.

5. Desai A, Sachdeva S, Parekh T, Desai R. COVID-19 and Cancer: Lessons From a Pooled MetaAnalysis. JCO Glob Oncol. 2020;6:557-9. doi:10.1200/G0.20.00097.

6. Liang W, Guan W, Chen R, Wang W, Li J, Xu K et al. Cancer patients in SARS-CoV-2 infection: a nationwide analysis in China. The Lancet Oncology. 2020;21(3):335-7. doi:10.1016/S14702045(20)30096-6.

7. Garassino MC, Whisenant JG, Huang L-C, Trama A, Torri V, Agustoni F et al. COVID-19 in patients with thoracic malignancies (TERAVOLT): first results of an international, registry-based, cohort study. The Lancet Oncology. 2020;21(7):914-22. doi:10.1016/S1470-2045(20)30314-4. 
8. Banna G, Curioni-Fontecedro A, Friedlaender A, Addeo A. How we treat patients with lung cancer during the SARS-CoV-2 pandemic: primum non nocere. ESMO open. 2020;5(2). doi:10.1136/esmoopen-2020-000765.

9. Passaro A, Addeo A, Von Garnier C, Blackhall F, Planchard D, Felip E et al. ESMO Management and treatment adapted recommendations in the COVID-19 era: Lung cancer. ESMO open. 2020;5(Suppl 3):e000820. doi:10.1136/esmoopen-2020-000820.

10. Luo J, Rizvi H, Egger JV, Preeshagul IR, Wolchok JD, Hellmann MD. Impact of PD-1 Blockade on Severity of COVID-19 in Patients with Lung Cancers. Cancer discovery. 2020;10(8):1121-8. doi:10.1158/2159-8290.cd-20-0596.

11. Bersanelli M. Controversies about COVID-19 and anticancer treatment with immune checkpoint inhibitors. Immunotherapy. 2020;12(5):269-73. doi:10.2217/imt-2020-0067. 